\title{
Objective measurement of rheumatoid arthritis using technetium index
}

\author{
E. C. HUSKISSON, JANE SCOTT, AND H. W. BALME \\ From the Department of Rheumatology, St. Bartholomew's Hospital, London EC1A 7BE
}

\begin{abstract}
Huskisson, E. C., Scott, J., and Balme, H. W. (1976). Annals of the Rheumatic Diseases, 35, 81-82. Objective measurement of rheumatoid arthritis using technetium index. The technetium index was measured in 22 patients with rheumatoid arthritis, before and after 6 months' treatment either with penicillamine or with anti-inflammatory drugs. The index was calculated by dividing the sum of the count rates over both knees and both wrists by the dose of technetium given. In the penicillamine group there was a significant reduction in the technetium index and the changes correlated well with some clinical measurements of improvement. It is suggested that the technetium index is a useful objective measure of the effects of drugs with a specific activity in rheumatoid arthritis.
\end{abstract}

The technetium index, based on the sum of the count rates over several joints, has been shown to correlate with some clinical measurements of disease severity (Oka, Rekonen, and Ruotsi, 1971; Huskisson and others, 1973) but has not been found to be responsive to anti-inflammatory drug therapy, not even to corticosteroids (Berry and Huskisson, 1974).

\section{Methods}

Twenty-two patients with classical or definite rheumatoid arthritis (RA) by the A.R.A. criteria (Committee of the American Rheumatism Association, 1959) were studied; all had active disease which had failed to respond to, or progressed despite, optimal anti-inflammatory drug therapy. Eleven patients were treated with penicillamine (doses increasing by $250 \mathrm{mg}$ fortnightly up to a maintenance dose of $1 \mathrm{~g}$ daily) and anti-inflammatory drugs, and 11 patients continued with anti-inflammatory drugs alone.

The technetium index was measured before the start of treatment and again after 6 months' treatment. Approximately $200 \mu \mathrm{Ci}$ technetium were injected intravenously and count rates recorded 20 minutes later over both knees and both wrists. Each joint was counted for 20 seconds. The syringe was counted before and after injection, the difference between the two counts representing the dose given. Technetium index was calculated as the sum of the count rates over the four joints divided by the dose and multiplied by 1000 for convenience.

Concurrently with the technetium studies a series of clinical measurements was made by an observer unaware of the patient's treatment and with whom the side effects of the treatment were not discussed. Measurements included pain, using a visual analogue scale, duration of morning stiffness, proximal interphalangeal joint size (Boardman and Hart, 1967), and articular index (Ritchie and others, 1968). Latex tests were carried out at the beginning and end of the study.

Changes in measurements within each group were analysed by Student's ' $t$ ' test applied to paired data. Correlation coefficients were calculated for changes in technetium index and changes in other measurements. Student's ' $t$ ' test was also used to test the comparability of the two groups at the start of the study.

\section{Results}

There was no significant difference between the two groups in any of the measurements made at the start of the study. There was a significant reduction in technetium index in patients receiving penicillamine but not in those receiving anti-inflammatory drugs (Table). There was also a significant reduction in latex test titres in the penicillamine group, but not in the anti-inflammatory group $(t=3.46 ; P<0.01)$.

Changes in technetium index showed a significant correlation with improvement in pain $(r=0.81$; $P<0.01)$ and joint circumference $(r=0.60 ; P<0.05)$, but not with articular index, duration of morning stiffness, or changes in latex test titre.

\section{Discussion}

Objective measurements of the severity and course of rheumatoid arthritis are badly needed especially in view of the unpredictable course of the disease and the striking effects which symptomatic therapy including placebos can have on the subjective manifestations. The technetium index seems to offer such a 
Table Mean technetium index ( \pm standard error) before and after 6 months' treatment with either penicillamine or anti-inflammatorydrugs

\begin{tabular}{llll}
\hline Treatment group & \multicolumn{2}{l}{ Mean Tc index } & $P$ \\
\cline { 2 - 3 } & Before & After & \\
\hline Penicillamine & $321 \cdot 3 \pm 15 \cdot 97$ & $243 \cdot 6 \pm 18.58$ & $<0.005$ \\
Anti-inflammatory drugs & $308 \cdot 6 \pm 32 \cdot 48$ & $270 \cdot 7 \pm 19.94$ & $>0 \cdot 1$ \\
\hline
\end{tabular}

measurement, being proportional to the severity of the disease process and responsive at least to one type of therapy.

Penicillamine is classified as a drug with a specific effect in rheumatoid arthritis (Huskisson, 1974). It differs from anti-inflammatory drugs in having effects on extra-articular manifestations of the disease, such as nodules, and on titres of rheumatoid factor. Its effects have been shown to be greater than those of anti-inflammatory drugs alone (Multicentre Trial
Group, 1973) including corticosteroids (Ott and Schmidt, 1976). Penicillamine therapy may reduce the technetium index either because it has a more fundamental effect on the disease process, accompanied by reduction in the volume of inflamed synovium, or simply because it has a much greater effect than anti-inflammatory drugs.

Clinical trials of drugs with this type of activity should now include measurement of technetium index.

\section{References}

Berry, H., ANd Huskisson, E. C. (1974) Ann. rheum. Dis., 33, 523 (Isotopic indices as a measure of inflammation in rheumatoid arthritis)

BoARdman, P. L., AND HART, F. D. (1967) Brit. med. J., 4, 264 (Clinical measurement of the anti-inflammatory effects of salicylates in rheumatoid arthritis)

Committee of the American Rheumatism Association (1959) Ann. rheum. Dis., 18, 49 (Diagnostic criteria for rheumatoid arthritis, 1958 revision)

Huskisson, E. C. (1974) 'Recent drugs and the rheumatic diseases' in 'Reports on Rheumatic Diseases', p. 54. Arthritis and Rheumatism Council, London

—, Berry, H., Browett, J. P., AND Balme, H. W. (1973) Ann. rheum. Dis., 32, 99 (Measurement of inflammation. 2. Critical evaluation of technetium clearance and infra-red thermography)

Multicentre Trial Group (1973) Lancet, 1, 275 (Controlled trial of D-penicillamine in severe rheumatoid arthritis)

OKa, M., Rekonen, A., AND Ruotsi, A. (1971) Acta. rheum. scand., 17, 27 (Tc-99m in the study of systemic inflammatory activity in rheumatoid arthritis)

OTt, V. R., AND SCHMIDT, K. L. (1976) (to be published) 'Treatment of rheumatoid arthritis with D-penicillamine. Preliminary results of a controlled clinical trial'. Paper read at International Symposium on Penicillamine, London, 1974

Ritchie, D. M., Boyle, J. A., McInnes, J. M., Jasani, M. K., Dalakos, T. G., Grieveson, P., and Buchanan, W. W. (1968) Quart. J. Med., 37, 393 (Clinical studies with an articular index for the assessment of joint tenderness in patients with rheumatoid arthritis) 